\title{
Modernisasi Pendidikan Islam di Indonesia Awal Abad Ke-XX: Kasus Muhammadiyah
}

\section{Palahuddin}

Universitas Muhammadiyah Mataram

Naskah diterima 21 Nov 2018, direvisi 17 Des 2018, disetujui 17 Jan 2018

Abstract This paper discusses about the modernization of education conducted by Muhammadiyah at the beginning of the 20th century circa 1911-1932. The modernization was initiated by the founde of Muhammadiyah Kiyai Haji Ahmad Dahlan, indeed effected by religious social conditions of Moslems at that moment which is still lagging behind in all aspects of life. For Muhammadiyah, to solve the problem is modernization of education. The modernization of education conducted by Muhammadiyah is a way of adapting the educational system of Netherlands in Islamic education. The form of the model of Muhammadiyah school is same as the model of Netherland school. The term of Aziyumardi Azra , referred to as "public school (Netherlands) plus" or Streenbrink referred to as "Ultra Conservative". In that new and modern school, in addition to religious studies, taught public lessons; the instruments of the study adopted directly as how Netherlands learning. Applied level system and school payment from students. As well as he most phenomenal is the teachers have been given incentives in the form of salary. All of this things, which we now see as something that is good, at that moment it is something very new, strange and even overwhelming.

Keyword: Muhammadiyah, Modernization, Education

Abstrak Artikel ini membahas tentang modernisasi pendidikan yang dilakukan oleh Muhammadiyah pada awal abad ke-20 sekitar tahun 1911-1932. Modernisasi yang digagas oleh pendiri Muhammadiyah, Kiyai Haji Ahmad Dahlan, sesungguhnya dilatarbelakangi oleh kondisi sosial keagamaan umat Islam saat itu yang masih tertinggal dalam seluruh aspek kehidupannya. Bagi Muhammadiyah, untuk mengatasi hal tersebut kuncinyamelalui modernisasi pendidikan. Modernisasi pendidikan yang dilakukan oleh Muhammadiyah ditempuh dengan cara mengadaptasi sistem pendidikan Belanda dalam 
pendidikan Islam. terbentuknya model sekolah Muhammadiyah seperti model sekolah Belanda istilah Azra, sebagai "Sekolah Umum (Belanda) Plus", atau Streenbrink sebagai "Sekolah Ultra Konservatif". Dalam sekolah baru dan modern itu,selain pelajaran agama, diajarkan juga pelajaran umum; instrumen belajar diadopsi langsung seperti cara Belanda; diberlakukan sistem penjenjangan dan pembayaran sekolah dari siswa; serta yang paling fenomenal adalah para guru telah diberikan insentif berupa gaji. Semua hal ini, yang kita lihat sekarang sebagai sesuatu yang biasa, pada saat itu merupakan sesuatu yang sangat baru, aneh dan bahkan luar biasa.

Kata Kunci:Muhammadiyah, Modernisasi, Pendidikan

\section{A. PENDAHULUAN}

Muhammadiyah didirikan oleh Kiyai Haji Ahmad Dahlan (selanjunya disingkat Kiyai Dahlan), pada tanggal 18 November 1912 Miladiyah bertepatan dengan 8 Dzulhijjah 1330 Hijriyah di Yogyakarta (PP Muhammadiyah, 2010:3). Kiyai Dahlan saat itu merumuskan 2 tujuan Muhammadiyah didirikan, yaitu pertama, menyebarkan ajaran Kanjeng Nabi Muhammad saw kepada penduduk bumi putera di dalam residensi Yogyakarta. Kedua, memajukan hal agama Islam kepada anggota-anggotanya. Namun, setelah mendapat pengesahan dari pemerintah Belanda pada tanggal 22 Agustus 1921, dan juga karena banyaknya tuntutan dari daerah-daerah lain di luar Yogyakarta, tujuan Muhammadiyah didirikan mengalami perubahan redaksional menjadi "memajukan dan menggembirakan hidup sepanjang kemauan agama Islam kepada sekutu-sekutunya (Nashir, 2000:64-65).

Dalam pandangan para peneliti, Muhammadiyah disebut dengan predikat yang beragam. Deliar Noer, James L. Peacock, William Sephard misalnya, menyebut Muhammadiyah sebagai gerakan modernis Muslim di Indonesia; Alfian dan Wertheim menamakannya sebagai gerakan reformis Islam; Abu Bakar Atjeh mengidentikkannya sebagai gerakan kembali kepada ajaran salaf; Clifford Geertz, George Kahin, dan Robert van Neil 
memasukkannya dalam kelompok gerakan sosiokultural pembaharuan (Nashir, 2010:1). Secara khusus, Wertheim menganggap Muhammadiyah sebagai gerakanmodernis tetapi liberal, kendati kemudian terlihat kaku dan mengarah pada revivalisme (Hidayatullah, 2000:57-67).

Mukti Ali, saat memberi kata pengantar buku "Matahari Terbit di Balik Pohon Beringin" buah karya Mitsuo Nakamura, menyatakan bahwa Muhammadiyah merupakan salah satu ormas (Organisasi Massa) Islam terbesar di Indonesia yang memiliki banyak wajah (dzu wujuh) (Muktiali, 1983:). Sebutan ini dimaksudkan untuk memberi ilustrasi bahwa Muhammadiyah sebagai ormas memiliki beragam aktifitas yang tidak hanya terbatas pada aspek keagamaan saja seperti asumsi masyarakat umum, tetapi juga dalam bidang pendidikan, ekonomi, sosial bahkan pernah terjun dalam bidang politik praktis. Tidak mengherankan jika kalangan di luar Muhammadiyah (outsider) kadang menyebut ormas ini dengan sebutan beragam pula, seperti sebagai organisasi keagamaan, organsisasi sosial dan organisasi pendidikan. Sebagai implikasinya, Muhammadiyah tercatat di berbagai instansi pemerintah, misalnya sebagai organisasi keagamaan di Kementrian Agama, sebagai organisasi sosial di Kementrian Sosial dan sebagai organisasi pendidikan di Kementrian Pendidikan. Bahkan pada tahun 1966, lewat surat wakil perdana menteri Bidang sospol dan Mendagri, Muhammadiyah pernah dinyatakan sebagai orsospol, yaitu organisasi massa yang memiliki fungsi politik riil dalam masyarakat Indonesia sebagaimana halnya partai politik (Syamsuddin, 1990:vii).

Predikat "banyak wajah" yang dilekatkan kepada Muhammadiyah ini sangat wajar dan logis, bahkan sangat obyektif, karena Muhammadiyah dalam bidang-bidang tersebut memiliki jumlah Amal Usaha yang sangat fantastis. Dalam laporanresmi Pimpinan Pusat (PP) Muhammadiyah saat Muktamar di Makassar tahun 2015 menyebutkan bahwa data pada tahun 2014Muhammadiyah telah memiliki amal usaha 
sebanyak 176 perguruan tinggi, 1143 SMA/ SMK/MA, 1772 SMP/ MTS, 2604 SD/ MI, 14346 TKABA-PAUD, 71 SLB, 102 pondok pesantren, 15 Sekolah Luar Biasa, 457 Rumah Sakit dan Rumah Bersalin, 421 Panti Asuhan, 82 Panti Berkebutuhan Khusus, 78 Asuhan Keluarga, 54 panti jompo, 437 BMT (Baitul Mal wa Tanwil), 762 BPRS (Bank Perkreditan Rakyat Syariah), 25 penerbitan dan berbagai amal usaha lainnya. Sebuah capaian yang membanggakan. Banyak tokoh dan institusi, baik nasional ataupun internasional, yang memberikan apresiasi yang setinggi-tingginya kepada Muhammadiyah atas kesusksesan ini. Azra misalnya menyebut Muhammadiyah sebagai the lagest Moslem organization in the world. Azra juga menyebut Muhammadiyah adalah ormas yang paling banyak memiliki lembaga pendidikan di Indonesia (Azra, 2012:177).

Makalah ini akan membahas tentang modernisasi pendidikan Muhammadiyah di masa-masa awal berdirinya awal abad ke-20 sekitar tahun 1911-1932. Dalam pandangan penulis, periode inilah modernisasi pendidikan Muhammadiyah mendapatkan momentum, karena di saat yang sama mayoritas umat Islam, termasuk lembaga pendidikan, di nusantara masih sangat tertinggal.Agar pemahaman tentang hal tersebut lebih komprehensif, penulis terlebih dahulu mendeskripsikan secara singkat tentang kondisi sosial keagamaan, termasuk pendidikan, sebelum dan saat Muhammadiyah berdiri.

Dalam artikel ini mengkaji Modernisasi Pendidikan Islam di Indonesia yang digagas Kiyai Haji Ahmad Dahlan pendiri pendidikan Muhammadiyah pada awal abad ke-20 sekitar tahun 1911-1932. Artikel ini mengambarkan bahwa Modernisasi dilatarbelakangi oleh kondisi sosial keagamaan umat Islam saat itu tertinggal dalam seluruh aspek kehidupannya. Dengan demikian melalui modernisasi pendidikan sebagai solusi dilakukan oleh Muhammadiyah ditempuh dengan cara mengadaptasi sistem pendidikan Belanda dalam pendidikan Islam. Hasilnya, terbentuklah model sekolah Muhammadiyah (Islam) disebut sebagai "Sekolah Umum (Belanda) Plus", atau "Sekolah Ultra 
Konservatif". Sekolah tersebut tidak hanya mempelajari agama, juga pelajaran umum; instrumen belajar diadopsi langsung seperti cara Belanda.

\section{B. PEMBAHASAN}

\section{Kondisi Sosial Keagamaan}

Sebelum Islam datang, masyarakat di Nusantara memiliki kepercayaan yang telah menyatu dengan sistem hidup mereka. Kepercayaan-kepercayaan itu adalah dinamisme, animisme, Hinduisme dan Budhaisme. Snouck Hurgronye menulis bahwa di Indonesia, terutama di Jawa, Sumatera Tengah dan Aceh, masyarakat percaya pada benda-benda gaib, suatu kepercayaan yang sebagian merupakan pikiran orang Polinesia, sebagian merupakan pikiran orang Hindu; slametan-slametan orang Jawa disajikan bagi semangat (jiwa) nenek moyang mereka, semangatsemangat yang dianggap melindungi desa-desa dan sawah-sawah; ia mengunjungi tempat keramat-keramat, kubur-kubur sakti dari wali-wali, diantaranya berasal dari keramat-keramat zaman pra agama; ia membakar kemenyan di bawah pohon-pohon yang dianggap sakti; bacaan-bacaan doannya penuh dengan namanama makhluk halus seperti demit, peri, dan periangan dan lainnya serta jin; Dalam hatinya ia sebenarnya orang-oarang yang tidak beragama (Noer, 1980:20). Contoh lain adalah munculnya buku-buku primbon dan astorologi.

Setelah Islam datang kepercayaan-kepercayaan itu tetap eksis dan tidak mudah dihapuskan, bahkan bercampur baur dengan ajaran Islam. Dalam kondisi seperti inilah Islam hadir dan berkembang menjadi ajaran yang berbeda dengan Islam yang murni sebagaimana diajarkan oleh Allah dan RasulNya, Muhammad saw. Menurut Kuntowijoyo, seperti dikutip oleh Khozin, sampai awal abad ke-20 kondisi Islam di Jawa memiliki dua corak besar, yaitu Islam sinkretis dan Islam Tradisionalis. Corak pertama dengan ciri-ciri yang menonjol adalah syirik dan takhayyul. Sedangkan yang kedua berada di lingkungan pesantren 
dengan kiyai sebagai pusatnya dengan ciri-ciri menonjol, yaitu bid'ah dan churafat (Khozin, 2005:21-22).

Terkait dengan paham keagamaam, Daliman menyebut ada 3 corak ajaran Islam yang berkembang saat awal masuknya Islam ke Indonesia, yaitu mazhab Syi'ah, Mazhab Syafii dan Mazhab hanafi. Pada abad ke-16, ajaran Syi'ah telah dijadikan sebagai ajaran resmi di Persia. Para penganut syi'ah banyak ditemukan di Perlak dan Samudera Pasai. Dalam catatan sejarah kerajaan Samudera Pasai sesungguhnya menganut paham syi'ah (Daliman, 2012:44-45). Ajaran syi'ah menganut paham tasauf, yaitu paham wujudillah (emanasi), dimana manusia adalah percikan dari sinar Ilahi. Ajaran ini dcetuskan oleh al-Hallaj. Saat itu, ajaran ini diikuti dan disebarkan oleh Hamzah Fansyuri dan Syamsuddin alSamatrani. Mukti Ali, seperti ditulis oleh Mustafa kamal Pasha, menyatakan bahwa ajaran tasauf merupakan sinkretis antara ajaran Islam dan Hindu. Hal ini juga yang menjadikan Islam lebih mudah diterima oleh masyarakat nusantara saat itu, karena ajaran tasauf lebih toleran terhadap adat kebiasaan yang hidup di suatu tempat, walapun bertentangan dengan ajaran Islam yang murni.

Adapun ajaran Syafiiyyah dibawa setelah Syi'ah lebih dahulu masuk dan berkembang. Dalam catatan sejarah, mazhab Syafii masuk ke Sumatera Timur dibawa oleh Syekh Ismail dari Mesir dan berhasil mengubah paham Kerajaan Samudera Pasai menjadi paham Syafiiyyah. Sejak itulah faham Syafiiyyah menyebar ke seluruh penjuru nusantara (Daliman, 2012:50-51).

Adapun Mazhab Hanafi berkembang di pantai utara pulau Jawa dibawa dari negeri Campa, sebuah kerajaan kuno di dataran Asia Tenggara yang terletak di Vietnam Selatan. Menurut Daliman, Kerajaan Demak menganut ajaran Hanafi, hal ini didasarkan pada kronik yang mengisahkan bahwa ketika Fatahillah sebagai panglima tentara Demak menyerang Cirebon pernah member gelar "Maulana Idil Hanafi" bagi seorang Muslim Cina yang telah berjasa dalam membantu merebut Cirebon.

Menurut hemat penulis, Daliman alpa atau lupa menyebut secara spesifik paham keagamaan dalam bentuk tasawuf atau 
tarekat yang berkembang di nusantara. Padahal temuan Azra dalam penelitiannya disebutkan bahwa pada abad XVII dan XVIII hampir merata paham agama yang berkembang di nusantara adalah tarekat atau tasawuf (Azra, 2013), bahkan hingga kini paham ini masih kuat di beberapa tempat, seperti Jawa Timur, dan di beberapa wilayah Sulawesi, Kalimantan dan lainnya.

Saat Islam tumbuh dan berkembang di Nusantara dengan berbagai dinamikanya, datanglah penjajahan bangsa eropa secara silih berganti. Mulai dari Spanyol, Portugis, Inggris, Belanda dan Jepang. Tulisan ini hanya akan membahas tentang penjajahan Belanda yang memiliki pengaruh yang sangat kuat di Indonesia, karena menjajah Indonesia dalam kurun waktu yang cukup lama.

Misi penjajahan Belanda pertama kali datang ke nusantara adalah untuk berdagang. Kegiatan perdagangan ini bertujuan untuk mengembangkan usaha bisnis mereka dalam bidang rempah-rempah yang akan dijual dengan harga tingggi di Eropa. Armada kapal Belanda pertama kali datang pada tahun 1595, kemudian yang kedua tahun 1598 dan yang ketiga pada tahun 1599 serta yang keempat pada tahun 1600 (Yatim, 1997:234).

Setelah banyak yang mengetahui bahwa hasil usaha mereka cukup menguntungkan, banyak Perseroan Amsterdam berdiri yang ingin berdagang dan berlayar ke Indonesia. Agar teroganisir secara baik, perseroan-perseroan itu disahkan oleh Staten General Republik untuk bergabung menjadi satu perseroan dengan nama VOC (Vereenigde Oost Indische Compagnie). Tetapi dalam piagam itu disebutkan, selain berdagang mereka diberi kewenangan untuk melakukan kegiatan politik untuk menunjang kegiatan dagang mereka.

Penetrasi politik Belanda semakin kencang saat mereka ingin melakukan monopoli dagang di Indonesia. Untuk mencapai tujuannya, mereka dibantu oleh kekuatan militer dan armada tentara yang lebih maju serta menerima hak-hak yang bersifat kenegaraan dari pemerintah Belanda untuk melakukan ekspaansi wilayah, mengadakan perjanjian politik, dan sebagainya. Taufik Abdullah mencatat bahwa pada abad ke-17 dan 18 disebut sebagai 
periode ekspansi dan monopoli Belanda di Indonesia (Abdullah, 1991:236-237).

Dalam perkembangan selanjutnya ternyata Belanda tidak hanya menjajah untuk kepentingan ekonomi, tetapi untuk kepentingan misionaris Kristen. Dalam sejarah motif penjajahan mereka dikenal dengan istilah 3 G, yaitu Gold, Glory dan Gospel. Gold yang berarti emas sebagai simbol ekonomi, untuk mengeruk kekayaan bangsa Indonesia dengan cara pemiskinan anak negeri jajahannya; Sedangkan Glory yang berti kejayaan sebagai simbol penguasa, untuk melakukan pembodohan agar anak negeri tetap buta terhadap jati dirinya yang berhak untuk merdeka. Adapun Gospel yang berarti injil untuk menjalankan program pemurtadan (konversi agama) untuk masuk agama Kristen. Dengan motif terakhir ini, Belanda sesungguhnya sedang menjalankan tugas suci (mission sacre) sebagai doktrin agama mereka untuk menyelamatkan domba-domba yang hilang

Terhadap realitas ini, kerajaan-kerajaan Islam mengadakan perlawanan terhadap Belanda. Kerajaan Mataram pernah 2 kali melakukan serangan ke Batavia. Kerajaan Banten juga merampas 2 kapal Belanda. Di Sulawesi, kerajaan Gowa, Tallo dan Makassar juga melakukan perlawanan terhadap Belanda. Di Sumatera, kerajaan-kerajaan Islam dengan cepat jatuh di bawah kekuasaan Belanda, kecuali Aceh. Usaha-usaha untuk melawan cengkraman dan penjajahan Belanda tidak pernah putus. Tetapi dapat dikatakan semuanya gagal. Badri Yatim menyebut 5 alasan kegagalan mengalahkan Belanda, yaitu: pertama Belanda dilengkapi dengan organisasi dan persenjataan modern, sementara kerajaan-kerajaan Islam masih menggunakan persenjataan tradisional; kedua Penduduk Indonesia masih tergantung kepada wibawa seorang pemimpin, sehingga saat pemimpinnya terbunuh atau ditangkap, praktis Belanda mendapatkan kemenangan; ketiga tidak ada persatuan antara kerajaan-kerajaan Islam di nusantara; karena keempat Belanda berhasil menerapkan politik adu domba; kelima dengan politik adu domba itu, banyak penduduk pribumi yang memerangi rekan- 
rekannya sendiri (Yatim, 1997:241-242). Untuk meningkatkan efektivitas perlawanan terhadap penjajah, berbagai upaya dilakukan oleh semua komponen bangsa. Salah satu komponen terpenting adalah memasukkan ideologi agama sebagai spirit baru untuk menentang dan melawan penjajah. Spirit baru inilah yang menjadi salah satu komponen semangat pembaharuan.

\section{Kondisi Pendidikan Islam}

Ada dua modelpendidikan sebagai representasi pendidikan Islam yang berkembang di Indonesia sejak masuknya Islam hingga memasuki abad ke-20, yaitu, yaitu model pesantren dan surau. Model pesantren tumbuh dan berkembang di Jawa, sedangkan surau di Sumatera.Kedua model pendidikan ini masih sangat tradisioal, konsevatif, kolot dan tidak memenuhi standar pendidikan Eropa (Riklefs, 2005:336-337).

Dari aspek manajemen, pesantren ataupun surau dipimpin oleh seorang Kiyai. Kiyai adalah figur tunggal dan sentral yang memiliki otoritas penuh dalam segala hal terhadap murid atau santrinya, bahkan masyarakat luas. Dalam pandangan kiyai, seperti disebut Dhofier, pesantren yang dipimpinnya seperti kerajaan kecil dan dirinya sebagai sumber mutlak atas seluruh kewenangan atau kekuasaan dalam kehidupan pesantren (Dhofier, 1994:56). Selain sebagai guru, kiyai adalah sosok yang sangat dihormati dan disegani serta dipercaya mampu memberikan berkah dan celaka, bahkan dianggap ma'shum (tanpa salah dan dosa). Selain itu, telah menjadi kebiasaan kiyai dijadikan sebagai tabib, hakim, konsultan magis dan sebagai tempat menggantungkan hidup dan masa depan para santri. Bagi santri, kehinaan dan ketundukannya kepada kiyai adalah sebuah kebanggaan, dan kerendahan hati terhadapnya adalah keluhuran. Itu sebabnya, seorang santri akan sangat bahagia dan bangga sekaligus dengan etos kerja tinggi bila dapat membantu kiyai menyelesaikan pekerjaan rumah tangga kiyaimisalnya.

Dari aspek proses pendidikan, hampir dipastikan metode pembelajaran dengan menggunakan metode ceramah yang 
monoton, tanpa dialog. Materi yang diajarkan hanya terfokus pada pelajaran agama seperti tertuang dalam kitab Islam klasik, misalanya terkait dengan praktik salat lima waktu, khutbah, salat jumat dan lainnya. Jika diklasifikasikan, kitab yang dipelajari di pesantren dapat dibagi menjadi 8, yaitu: nahwu, sharaf, fikih, usul fikih, hadis, tafsir, tauhid, tasawuf dan etika, serta cabang-cabang yang lain seperti tarikh, dan balaghah (Dhofier, 1994:49-50). Dari 8 jenis kitab tersebut, pengajaran fikih, nahwu, sharaf dan akidah menjadi prioritas. Sedangkan pengajaran tasauf, tafsir al-Qur'an, dan juga hadis sebagai ilmu yang bersifat sophisticated, yang hanya dapat dipelajari oleh orang-rang tertentu (Madjid, 1997:93). Tidak ditemukan kitab/ buku umum sebagai bahan ajarnya.

\section{Gelombang Modernisasi}

Modernisasi di Dunia Islam pertama kali terjadi tahun 1803 di Sumatera Barat, Minagkabau. Saat itu, Haji Sumanik, Haji Piobang dan Haji Miskin baru pulang dari Mekah setelah selesai menunaikan ibadah haji membawa semangat ajaran Wahhabi. Tentang bagaimana mereka terpengaruh ajaran Wahhabi diceritakan oleh para sejarahwan bahwa jamaah haji sebelum pulang ke Indonesia mereka bermukim dan belajar agama di Mekkah. Menurut informasi Aqib Suminto, saat itu memang jika masyarakat ingin menunaikan ibadah haji harus dengan menumpang kapal laut. Mereka menghabiskan waktu berbulanbulan di atas kapal laut menantang maut dengan penuh penderitaan. Setelah selesai menunaikan ibadah haji, para jamaah haji tidak bisa langsung pulang ke tanah air, karena mereka harus menunggu jadwal kedatangan kapal yang akan mengangkut kepulangannya. Saat mereka menunggu inilah dipergunakan untuk mengikuti kajian-kajian keagamaan yang bervariasi di Tanah Suci. Ada yang mengajarkan ajaran Wahabi, ada juga yang mengajarkan faham yang bermazhab Syafiiyyah (Suminto, 1996:92-93).

Salah seorang tokoh ternama asal Bukit Tinggi yang tinggal menjadi penduduk Mekah dan memiliki kedudukan prestesius 
sebagai Imam mazhab Syafii di Masjid Haram bernama Syekh Ahmad Khatib. Disamping itu, ia menyetujui aliran Tarekat Naqsabandiyah. Ia mulai belajar di Mekkah sejak tahun 1855, saat usianya 21 tahun. Meskipun memiliki kedudukan yang tinggi, ia seorang yang familiar, cerdas, toleran dan terbuka, sehingga banyak murid-muridnya berasal dari Indonesia. Karena toleran dan terbuka, ia memberikan kekebasan murid-muridnya untuk membaca dan mempelajari kitab-kitab yang ditulis oleh para pembaharu di dunia Islam saat itu, seperti tafsir al-Manar yang ditulis oleh Muhammad Abduh dan Rasyid Ridha dan Majalah Urwatul Wutsqa yang diterbitkan oleh Jamaluddin al-Aghani dan Muhammad Abduh. Tujuannya agar setelah mengetahui ide-ide pembaharuan tersebut para muridnya dapat meng-counter, menentang dan menolaknya. Murid-muridnya yang tetap menolak ide-ide pembaharuan tersebut dan tetap memegang teguh mazhab Syafii antara lain adalah Syekh Sulaiman ar-Rasuli, KH. Hasyim Asy'ari (pendiri NU) dan sebagainya. Sementara murid yang lain di luar dugaan bukannya menolak ide-ide pembaharaun tersebut, tetapi menerimanya bahkan menjadi pembelanya. Mereka adalah Syekh Muhammad Jamil Jambek, Abdul Karim Amrullah, Abdullah Ahmad, KH. Ahmad Dahlan (pendiri Muhammadiyah) dan lainya.

Dengan demikian $\mathrm{KH}$. Ahamd Dahlan adalah teman sekaligus sahabat KH. Hasyim Asy'ari. Mereka sama-sama menjadi murid Syekh Ahmad Khatib. Pada awal abad ke-20 gelombang modernisasi Islam di Indonesia semakin meluas. Secara kronologis, organisasi Islam modernyang didirikan di Indonesia saat itu, adalah: Pertama, Jami'at Khair, berdiri pada 15 Juli 1905. Kedua, Muhammadiyah berdiri pada 18 Nopember 1912, Ketiga, Al-Irsyad, berdiri pada 6 September 1914. Keempat, Persatuan Islam (Persis). berdiri pada 12 Seprember 1923, dan NU pada 31 Januari 1926. Adapun contoh gerakan Islam reformis di bidang politik adalah Sarekat Islam (SI). Nama ini kemudian berubah menjadi Partai Sarekat Islam pada tahun 1921 dan berubah lagi menjadi Partai Syarikat Islam Indonesia (PSSI) pada tahun 1930. 


\section{Modernisasi Pendidikan}

Berbagai uraian sebelumnya tentang kondisi sosial kegamaan di nusantara membawa Kiyai Dahlan menggagas urgensi modernisasi pendidikan. Kuntowijoyo menyatakan bahwasaat Muhammadiyah baru lahir sesungguhnya menghadapi 3 front, yaitu tradisionalisme (pesantren dan kiyai), Jawaisme (animisme dan dinamisme) dan modernisme (penjajahan Belanda). Tradisionalisme dihadapi oleh Kiyai Dahlan dengan tabligh (menyampaikan) dengan mencari dan mengunjungi murid. Melalui tabligh secara langsung berimplikasi kepada perlawanan terhadap idolatri (pemujaan tokoh), dan secara tidak langsung melawan mistifikasi(agama dibuat misterius). Sedangkan Jawaisme dihadapi dengan positive action (mengedepankan amar makruf, mengurangi nahi munkar). Adapun modernisme dihadapi salah satuya dengan pendidikan melalui pendidirian sekolahsekolah (Kuntowijoyo dalam Mulkhan, 2000 :xiii-xvii).

Dalam pandangan Kiyai Dahlan, keterbelakangan yang dihadapi oleh umat Islam sebenarnya akibat dari kebodohan, karena itu untuk mengatasinya, menurutnya, harus melalui pendidikan. Menurutnya ada 3 nilai dasar pendidikan yang harus ditegakkan untuk membangun sebuah bangsa, yaitu pertama, Pendidikan Akhlak, sebagai ikhtiar menanamkan karakter yang berlandaskan Al-Qur'an dan hadis. Kedua, Pendidikan Individu, sebagai upaya menumbuhkan kesadaran individu yang utuh, yang seimbang antara kebutuhan jasmani dan rohani, keyakinan dan intelektualitas, prasaan dan akal, dunia dan akhirat. Ketiga, Pendidikan Sosial, sebagai usaha untuk menumbuhkan kesediaan dan keinginan hidup bermasyarakat (Hidayat dkk, 2014:185).

Sebagai seorang "alumni tanah suci" yang terpengaruh dengan pembaharuan Islam, Kiyai Dahlan mulai merintis sistem penddidikan yang berbeda dengan sistem pendidikan saat itu. Ia tidak menolak 2 sistem pendidikan yang sedang berkembang saat itu, yaitu sistem pendidikan pesantren dan Belanda. Tetapi berusaha membuat terobosan baru dan mendesain sistem baru dalam bentuk konvergensi, yaitu mengadaptasikan sistem 
pendidikan pesantren dengan model sekolah Belanda. Sebagai realisasinya, langkah pertama yang ia lakukan adalah dengan mengadopsi sistem pendidikan Barat (Belanda), terutama terkait dengan metode belajar, sementara isinya tetap Islam (Maarif, 1993:145). Azra menyebut model pendidikan ala Muhammadiyah dengan "Sekolah Umum (Belanda) Plus" (Azra, 2012:36).

Dengan melakukan konvergensi, Kiyai Dahlan sesungguhnya ingin memecahkan ketegangan antara agama dan kemajuan (Kuntowijoyo, 2008:350), dimana saat itu memang Islam identik dengan kemunduran, sementara Barat identik dengan kemajuan. Ia yakin dengan konvergensi sistem pendidikan ini akan dapat mengubah kondisi (nasib) umat Islam. Melalui sistem pendidikan "yang baru" inilah akan dijadikan sebagai pintu masuk merubah cara berpikir umat Islam sehingga menjadi modern. Ia yakin betul dengan modernisasi pendidikan akan menjadi obat mujarab yang mampu berfungsi sebagai alternatif dan pemecah kebuntuan antara agama dan kemajuan.

\section{Pendirian Madrasah Modern}

Pada tanggal 1 Desember 1911, artinya satu tahun sebelum Muhammadiyah berdiridan setelah Kiyai Dahlan pulang dari ibadah haji yang ke-2, ia membangunMadrasah Diniyyah Ibtidaiyyah di rumahnya (Steenbrink, 1986:52). Madrasah Ibtidaiyyah yang dibangun oleh Kiyai Dahlan merupakan perpaduan antara pesantren dan sekolah Belanda. Ia ingin mengadopsi spirit keislaman yang dikembangkan di pesantren di satu sisi, dan pada sisi yang lain instrumen dan kurikulumnya ia ingin mengadaptasikannya dari sistem sekolah Belanda.

Madrasah ini merupakan pendidikan Islam modern pertama di Kraton Yogyakarta yang yang oleh Steenbrink disebut ultra konservatif. Pendirian Madrasah ini sesungguhnya terinspirasi setelah Kiyai Dahlan memiliki pengalaman mengajar agama di Sekolah Guru (Kweekschool)Jetis dan Sekolah Pendidikan Dokter atau STOVIA (School tot Opleiding van Indische Artsen) Magelang saat bergabung dan menjadi anggota aktif Budi Utomo (Mu'arif, 
2012:72). Disamping itu, gagasan untuk mendirikan madrasah ini ter-ilham saat Kiyai Dahlan menjadi anggota pasif Jami'at Khair, dimana ia sangat setuju dengan ide pembaharuan dan atmosfir intelektual yang berkembang di sanaserta dapat mendirikan sekolah modern.

Materi pelajaran yang diajarkan di Madrasah Diniyah ini lebih banyak diadopsi dari karya pembaharu Islam, seperti tauhid, tafsir, dan ilmu falak yang menjadi salah satu bidang kompetensi khusus Kiyai Dahlan. Hal pertama dilakukan oleh Kiyai Dahlan adalah mendesain kurikulum dan intrumen belajar secara modern yang diadopsi dari model pendidikan Belanda. Untuk pertama kalinya sebuah madrasah di Yogyakarta mengajarkan pelajaran umum dan agama secara bersamaan. Selain itu, instrument belajarnya mengikuti cara Belanda, yaitu menggunakan papan tulis yang terbuat dari kayu suren dan bangku dari kayu jati bekas mori, yang semua biaya pengadaannya dari uang pribadi Kiyai Dahlan (Setiawan, 2015:169). Karena madrasah ini seperti sekolah Belanda, di tengah masyarakat ia mendapat cacian dan olokolokan, bahkan ada yang menganggapnya sebagai orang yang telah murtad dan Kristen, dituduh kafir dan sebagai Kiyai palsu serta Kristen Alus, karena mengikuti model pendidikan kafir (Darban, 2000:37). Hal lain yang sangat tidak lazim saat itu adalah ketika Kiyai Dahlan sebagai seorang kiyai mencari murid di tengah masyarakat, pada saat yang sama seorang kiyai yang berilmu dan mencari murid dianggap sebagai sebuah aib sosial.

Meskipun murid telah mulai banyak berdatangan untuk masuk ke Madrasah ini, tatapi karena keaktifan Kiyai Dahlan di organisasi membuat aktifitas belajar dan mengajar menjadi terbengkalai. Akhirnya setelah kurang lebih 2 tahun madrasah ini bubar. Meskipun telah bubar, karena mengajarkan ilmu umum dan memiliki tiga jenjang kelas, madrasah ini telah disamakan posisinya dengan sekolah setaraf Sekolah Ongko Loro (Volkschool) pada tahun 1914 dan diberi subsidi oleh pemerintah. Tahun 1916 madrasah yang telah bubar itu berdiri lagi dan telah berganti nama menjadi VolkschoolMuhammadiyah Kauman Yogyakarta. 
Setelah mendapatkan bantuan tanah di Suronatan dari Sultan Yogyakarta, Volkschool Muhammadiyah di bagi menjadi dua, gedung sekolah yang di Kauman untuk murid perempuan, sedangkan yang di Suronatan untuk murid laki-laki. Seiring perkembangan waktu, Volkschool Muhammadiyah yang di Kauman berubah menjadi Sekolah Pawiyatan Muhammadiyah, sementara yang di Suronatan diganti menjadi Standart School Muhammadiyah, yang sekarang ini dikenal dengan SD Muhammadiyah Suronatan.

\section{Pendirian Sekolah Guru Modern}

Pada tahun 1919 Kiyai Dahlan mendirikan sekolah calon guru yang diberi nama Al-Qismul Arqa', yang diorientasikan untuk memenuhi kebutuhan para guru agama di sekolah-sekolah (rendah) Muhammadiyah (Riklefs, 2005:346). Secara etimologis, Al-Qismul Arqa' berarti bagian pertumbuhan. Pendirian lembaga ini sesungguhnya sebagai "kelas lanjutan" dari jenjang Standaarchool. Murid-murid Al-Qismul Arqa' secara khusus dibimbing, dibina dan dididik untuk menjadi calon guru. Materi pelajaran dalam kelas Al-Qismul Arqa' tidak jauh berbeda dengan pesantren tradisional saat itu yang hanya mengajarkan agama. Namun demikian, media pembelajaranya telah menggunakan papan tulis yang diadopsi dari sistem pendidikan Belanda. Hal yang paling fenomenal adalah dari 9 atau 8 jumlah muridnya terdapat 3 orang perempuan, di saat kaum perempuan tidak lazim untuk masuk sekolah.

Al-Qismul Arqa'pada dasarnya adalah jenis pendidikan Islam tradisional. Al-Qismul Arqa' hanya mengajarkan ilmu-ilmu agama, karena memang tujuan praktisnya adalah untuk menyediakan para tenaga guru agama di sekolah-sekolah Muhammadiyah. Ketentuan yang ada menyebutkan bahwa pelajaran umum baru boleh diajarkan setelah lembaga ini nanti berganti nama.

Pada tahun 1920, Hoodfbestuur Muhammadiyah (Pengurus Besar Muhammadiyah) merasa perlu membentuk bagian (majelis) yang secara khusus membantunya dalam menggerakkan roda 
Muhammadiyah, terutama dalam bidang-bidang tertentu yang dibutuhkan saat itu. Untuk kepentingan tersebut, pada tahun itu juga dibentuk 4 Bagian Hoodfbestuur Muhammadiyah, yaitu Bagian Tabligh dengan ketua H.M. Fachruddin, Bagian Taman Pustaka dengan ketua H.M. Mochtar, Bagian Penolong Kesengsaraan Umum (PKU) dengan ketua H. M. Syuja' dan Bagian Sekolahan yang dikutai oleh $\mathrm{H}$. Hisyam. Semua pengurus bagian ini dilantik langsung oleh Kiyai Dahlan. Dengan terbentuknya Bagian Sekolahan, Seluruh sekolah Muhammadiyah kini berada di bawah manajemen Bagian ini, yang sebelumnya langsung di bawah manajmen Hoodfbestuur Muhammadiyah.

Penetapan H. Hisyam menjadi Bagian Sekolahan membawa dampak positif bagi perkembangan sekolah Muhammadiyah. Ia memiliki tekad yang kuat untuk memajukan sekolah agama maupun umum. Tekadnya ini didukung oleh keahliannya di bidang administrasi dan manajemen, selain ia juga dikenal memiliki kompetensi dalam bidang hukum Islam.Saat itu juga, ketika menyampaikan visi misi tatkala dilantik menjadi Ketua Bagian Sekolahan, ia menyampaikan inisiatif untuk mendirikan Universitas seperti yang dibangun oleh Belanda, Technische Hogeschool, dengan tujuan melahirkan sarjana-sarjana Muslim yang mampu berkompetisi dengan sarjana lulusan Technische Hogeschool. Ia juga mulai mengambil kebijakan agar sekolahsekolah Muhammadiyah dapat selaras dengan kebijakan pemerintah. Ia berpendapat bahwa sekolah di Muhammadiyah memiliki dua kelebihan, yaitu memiliki ilmu pegetahuan umum seperti di sekolah Belanda, dan memiliki ilmu agama yang menjamin terpeliharanya komitmen keagamaan.

Pada tahun 1921, Al-Qismul Arqa' berganti nama menjadi Pondok Muhammadiyah. Putera Kiyai Dahlan yang bernama Kiyai Haji Siradj Dahlan dipercaaya untuk memipin Pondok Muhammadiyah. Untuk menjadikan pondok Muhammadiyah sebagai institusi pendidikan Islam modern, Kiyai Siradj dibantu oleh Ng. Djojosoegito, sebagai Juru Tulis I dan Moh. Hoesni sebagai Juru Tulis II. Selain telah masuk menjadi anggota 
Hoofdbestur Mohammadiyah. Mereka adalah para inelektual bumiputera lulusan sekolah Belanda yang telah dikenal ahli dalam bidang administrasi.

Mekipun nama pondok masih digunakan sebagai nama institusi pendidikan, namun pondok Muhammadiyah berbeda jauh dengan Al-Qiamul Arqa' dan pondok pesantren pada umumnya, terutama pondok tradisional (salafi), karena pondok ini telah berhasil mengintegrasikan ilmu-ilmu umum dan agama dalam kurikulumnya. Pada masa itu, hal ini masih menjadi sesuatu yang sangat asing bagi masyarakat sekitar. Atas dasar ini Amir Hamzah Wirjosukarto dalam penelitiannya menyimpulkan bahwa pondok Muhammadiyah adalah institusi pendidikan Islam modern pertama, bahkan satu-satunya yang menggunakan kurikulum dan manajemen modern di Yogyakarta(Wirjosukarto, 1968:119).

Dengan dukungan Sumber Daya Manusia (SDM) yang mumpuni dan menajemen modern menjadikan Pondok Muhammadiyah dapat dikatakan sebagai institusi pendidikan yang sangat maju pada waktu itu. Pondok Muhammadiyah tidak lagi dibawah manajemen langsung Hoofdbestur Mohammadiyah, tetapi dibawah Bagian Sekolahan. Kolaborasi antara haji Hisyam (Ketua Bagian Sekolahan), Djojosoegito (Juru Tulis I), R. Soesrosegondo (anggota bagian sekolahan), dan Siradj Dahlan (Direktur Pondok Muhammadiyah) menjadikan pondok Muhammadiyah menjadi semakin terkenal.

Di Pondok Muhammadiyah, selain mengintegrasikan ilmu agama dan ilmu umum, metode pembelajarannya tidak hanya menggunakan sistem klasikal, tetapi telah dipadukan dengan sistem internaat (pondok). Di Pondok Muhammadiyah juga berlaku sistem pesantren, yang mana para santri harus tinggal di asrama. Pelajaran agama tidak hanya disampaikan secara formal lewat proses pembelajaran di kelas, tetapi juga lewat asrama yang dijaga oleh para guru. Ilmu-ilmu umum disampaikan di kelas dengan metode pembelajaran modern. Lama pendidikan ditetapkan selama 5 tahun, dengan persyaratan harus lulus pada ujian yang diselenggarakan pada setiap tingkatan. Murid-murid 
yang telah lulus ujian pada tingkatan akhir (kelas 5) akan diberikan ijazah.

Memasuki tahun 1922, Pondok Muhammadiyah diproses menjadi sebuah institusi pendidikan yang lebih modern dengan nama Kweekschool Islam. Kweekschool Islam yang dikemudian hari dikenal dengan nama Kweekschool Moehammadijah berubah menjadi sekolah modern dengan ciri khas keislaman ala Muhammadiyah. Kweekschool Moehammadijah inilah yang hinggasaat ini bertahan menjadi Madrasah Muallimin Muhammadiyah Yogyakarta.

Model Kweekschool Moehammadijah pada tahun 1922 sudah sangat maju. Mu'arif mengutip dari Suara Muhammadiyah No. 1 Th, Ke-3/1922, terlihat bagaimana struktur pengajaran yang diberlakukan saat itu sudah sangat sistematis, seperti berikut:

Dari rencana pengajaran tersebut sangat jelas struktur pengajaran yang akan diterapkan. Mata pelajaran telah diklasifikasikan berdasarkan level kelas, lengkap dengan alokasi waktunya. Hal ini menunjukkan bahwa pemahaman Muhammadiyah tentang kurikulum dan pembelajaran secara khusus dan pendidikan secara umum sangat komprehensif. Berdasarkan struktur rencana pengajaran tersebut juga nampak bahwa sistem pembelajaran yang diberlakukan pada Kweekschool Moehammadijah adalah sistem pembelajaran modern yang memadukan pengetahuan agama dan pengetahuan umum. Dalam istilah yang lebih modern, model kurikulum yang digunakan adalah kurikulum terpadu, sedangkan model sekolah yang dikembangkan adalah sekolah terpadu.

Khusus untuk pelajaran, Kweekschool Moehammadijahtelah mulai mengadopsi mata pelajaran yang tidak lazim, bahkan menjadi tabu, karena dianggap haram. Pelajaran menggambarmisalnya, masih menjadi pelajaran yang kontroversial pada waktu itu. Mayoritas ulama, baik tradisional maupun modernis, saat itu menolak pelajaran ini dan menganggapnya sebagai sesuatu yang dilarang. Namun demikian, Muhammadiyah memiliki pendapat berbeda dengan pendapat 
mayoritas. Pada faktanya, dalam setiap momentum kongres Muhammadiyah pasca wafatnya Kiyai Dahlan sudah terbiasa memasang foto atau lukisan pendiri Muhammadiyah tersebut. Demikian juga pelajaran ilmu Tabi'i (natuurkennis) atau ilmu psikologi, Muhammadiyah telah mengajarkannnya kepada muridmurudnya di saat tradisi pesantren belum mengajarkannya kepada para santri.

Mu'arif juga mengutip daftar guru yang mengajar pada Kweeckschool Moehammadijah saat itu: Terkait dengan biaya operasioanl sekolah, berdasarkan data yang ditemukan oleh Mu'arif, sumber-sumber pendanaan Kweekschool Muhammadiyahdimobilisir dari kas Hoofdbestuur Muhammadiyah, infaq anggota, donator/dermawan, sumbangan operasionaal dan iuran bulan (SPP) dari murid. Para donator mayoritas berasal dari warga Muhammadiyah yang berprofesi sebagai pengusaha (pedagang batik, percetakan, took sembako, dan lain-lain). Yang paling menarik adalah KweekschoolMuhammadiyah telah memungut biaya pendaftaran penerimaan siswa baru (examen) sebesar f. 2.50 (dua setengah florin) dan menetapkan biaya operasional yang dibayarkan sewaktu pembayaran.

Pada tahun 1922 juga Muhammadiyah juga mengeluarkan ketentuan yang cukup mengejutkan, yaitu memberikan gaji kepada para guru (Syuja', 2009:163). Dalam Suara Muhammadiyah yang diterbitkan tahun 1923 dan 1924, seperti dikutip Farid Setiawan, menyebutkan bahwa gaji untuk kepala sekolah, pembantu kepala sekolah dan guru telah ditetapkan sedemikian rupa, yang besarannya sesuai dengan tanggungjwab, masa kerja dan beban kerja masing-masing, serta dibayarkan setiap bulan. Kebijakan Muhammadiyah yang memberikan gaji ini melawan kebiasaan sekolah Islam saat itu, karena gaji bagi guru yang mengajar di sekolah Isam adalah masalah etis dan sensitif. Seperti diketahui, kiyai tradisional pesantren berpendapat bahwa ilmu tidak untuk diperjualbelikan, apalagi untuk memperkaya diri sendiri. Oleh sebab itu pandangan mayoritas yang berkembanga adalah guru haram hukumnya menerima gaji. 
Pada tanggal 23 Februari 1923, Kiyai Dahlan meninggal dunia. Sang Kiyai yang telah merintis sekolah Al-Qismul Arqa' tidak sempat menyaksikan kesuksesan yang diraih oleh Pondok Muhammadiyah dibawah kepemimpinan puteranya, Siradj Dahlan. Ia belum sempat melihat bagaimana ide besarnya untuk menggagas sekolah modern kini sudah tampak nyata. Integrasi kreatif model pendidikan pesantren dengan sekolah umum yang diprakktikan oleh Pondok Muhammadiyah telah membawa persepsi baru di kalangan umat Islam bahwa lulusan pondok pesantren tidak hanya menguasai agama Islam, tetapi juga memiliki ilmu umum dan kecakapan hidup.

Pada tanggal 15 Juli 1923, Hoodfbestuur Muhammadiyah menetapkan berdirinya Department van Onderwijs Moehammadijah,unit khusus Bagian Sekolahan yang sebelumnya dipimpin oleh H. Hisyam. Departemen dengan dipimpin oleh Ngabehi (Ng.) Djojosoegito dengan tugas mengurus permasalahan di sekolah-sekolah Muhammadiyah, terutama terkait dengan standarisasi materi, metode dan kurikulum yang digunakan di setiap jenjang sekolah Muhammadiyah. Sekitar 2 bulan kemudian, tepatnya pada tanggal 15 September 1923,Hoodfbestuur Muhammadiyah secara mengejutkan menetapkan pendirian Madjelis Pimpinan Pengadjaran Moehammadijah, dengan pimpinan 3 orang, yaitu Ng. Djoejosoegito, R. Sosrosoegondo dan H. Hisyam. Penunjukan 3 orang ini semakin memantapkan sekolah Muhammadiyah menjadi sekolah modern. Pada tanggal 12 Maret 1924, K.H. Ibrahim, ketua Hoodfbestuur Muhammadiyah saat itu, sudah mengeluarkan ketentuan pendirian sekolah, sistem belajar, hari libur, kualifikasi guru dan murid, sanksi terhadap pelenggaran disiplin, biaya sekolah, kepala sekolah, dan administrasi sekolah.

Pada tahun 1923, "Pengoeroes Besar Muhammadijah" membentuk Comite Pendirian Roemah Kweekschool Islam (CPRKwl) yang dipimpin oleh Haji Mochtar. Comite atau panitia ini bertanggungjawab untuk menggalang dana sekitar $88.000 \mathrm{f}$ untuk rencana pembangunan gedung Kweekcshool Islam. Kweekschool 
Muhammadiyah menetapkan model pendidikan baru, yaitu selama 6 tahun. Para siswa akan mendapat ijazah setelah lulus seperti pada podok Muhammadiyah sebelumnya. Karena tidak mendapat pengakuan dari pemerintah Belanda, ijazah lulusan Kweekschool Muhammadiyah tidak diakui. Namun demikian, hal tersebut tidak menjadi masalah bagi para siswa, karena mereka telah mendapat indoktrinasi bahwa mereka harus siap menjadi "anak panah" Muhammadiyah yang siap dilesatkan kapanpun dan dimanapun untuk memenuhi panggilan dakwah demi mengemben misi persyarikatan Muhammadiyah.

Namun demikian, kemajuan yang didapatkan oleh Kweekschool Muhammadiyah bukan tampa hambatan. Pemerintah Belanda memberlakukan peraturan ordonansi guru (Goroe Ordonantie). Peraturan ini bertujuan untuk membatasi jumlah guru-guru di sekolah swasta (partikelir) di tanah air. Selain itu, guru-guru agama juga diseleksi secara ketat. Hal inilah yang membuat Muhammadiyah mengalami banyak kesulitan. Melalui Haji Fachrodin, tahun 1923 Muhammadiyah melakukan protes keras terhadap Belanda, karena menurutnya peraturan itu hanya bungkus dari politik kritenisasi.

Pada tanggal 11 Maret 1930, HoofdbestuurMuhammadiyah mulai membagi Kweekschool Muhammadiyah menjadi 2, yaitu Kweekschool Muhammadiyah Laki-laki di Ketanggungan, dan Kweekschool Muhammadiyah Isteri di Notoprajan.

Pada tanggal 1 Januari 1932, Kweekschool Muhammadiyah berganti nama menjadi "Madrasah Mu'allimin Muhammadiyah" untuk putra, dan "Madrasah Mu'allimat Muhammadiyah" untuk puteri hingga sekarang.Pergantian nama ini setelah Pemerintah Belanda mengeluarkan kebijakan Ordonansi Sekolah Liar pada tahun 1923, yang menekankan eksistensi sekolah-sekolah swasta pribumi.

Seiring berjalan waktu, Madjelis Pimpinan Pengadjaran Moehammadijah, yang membantu Hoodfbestuur Muhammadiyah dalam maslah pendidikan, mulai disesuaikan nomenklaturnya dengan nomenklatur yang ada di pemerintahan. Nama mejelis 
inipun berganti-ganti, mulai dengan nama: Majelis Penidikan, Majelis Pendidikan dan Pengajaran, kemudian Majelis Pendidikan dan Kebudayaan. Karena Muhammadiyah telah memiliki banayak perguruan tinggi, maka mulai tahun 1985 hingga sekarang majelis ini dipecah menjadi 2, yaitu Majelis Pendidikan Dasar dan Menengah (Dikdasmen) dan Majelis Pendidikan Tinggi (Dikti).

\section{KESIMPULAN}

Muhammadiyah lahir pada momentum yang tepat. Di saat umat Islam telah masuk ke dalam sistem sosial yang membelenggu dan merendahkan eksistensi mereka, Muhammadiyah datang membawa gerakan pencerahan (at-tanwir) yang membawa semangat api perubahan. Tidak hanya gagasan dan idealisme yang ditawarkan oleh Muhammadiyah, tetapi juga aktualisasinya dalam kehidupan nyata. Islam yang dipahami oleh Muhammadiyah adalah Islam yang dihayati, danhidup serta dipraktikkan dalam kehidupan sehari-hari.

Tahun 2017 ini Muhammadiyah telah memasuki usianya yang ke-104.Dalam usianya yang panjang yang penuh dinamika, Muhammadiyah telah banyak memberikan kontribusi nyata bagi negara kita tercinta. Kini Muhammadiyah bukan lagi dianggap oleh masyarakat awam sebagai organisasi yang aneh, apalagi kafir. Gagasan-gagasan dan kiprahnya, terutama dalam bidang pendidikan, telah banyak menjadi inspirasi bagi ormas-ormas lain baik di tingkat nasional maupun internasional.

Bagi Muhammadiyah, lembaga pendidikan merupakan salah satu intrumen untuk melakukan transformasi dalam kehidupan sosial. Itu sebabnya Nakamura menyebut 3 nilai penting moderninasi pendidikan dalam Muhammadiyah, yaitu pertama, prndidikan Muhammadiyah telah berhasil membangkitkan semangat nasioal bercorak Islam.Kedua, pendidikan Muhammadiyah telah berhasil menjadi instrumen efektif untuk menyebarkan ideologi pembaharuan Islam. Ketiga, pendidikan Muhammadiyah berperan besar menyebarkan pengetahuan praktis sains modern. 


\section{DAFTAR PUSTAKA}

Abdullah, T. (Ed.). 1991. Sejarah Umat Islam Indonesia. Jakarta: Majelis Ulama Indonesia

Aqib, S. 1996. Politik Islam Hindia Belanda. Jakarta: LP3S

Azra, A.2012. Pendidikan Islam: Tradisi dan Modernitas di Tengah

Tantangan Milenium III. Jakarta: Kencana

- 2013.Jaringan Ulama Timur Tengah dan Kepulauan

Nusantara Abad XVII dan XVIII. Jakarta: Kencana

Daliman, A. 2012.Islamisasi dan Perkembangan Kerajaan-Kerajaan Islam di Indonesia. Yogyakarta: Ombak

Darban, A. 2000. Sejarah Kauman: Menguak Identitas Kampung Muhammadiyah, Yogyakarta: Terawang

Dhofier, Z. 1994.Tradisi Pesantren: Studi tentang Pandangan Hidup Kiyai. Jakarta: LP3ES

Hamzah, A. 1968. Wirjosukarto, Pembaharuan Pendidikan \& Pengadjaran Islam jang Diselenggarakan oleh Pergerakan Muhammadijah. Malang: Ken Mutia

Hidayat, S. dkk. 2014. Studi Kemuhammadiyahan: Kajian Historis, Ideologis dan Organisatoris. Universitas Muhammadiyah Surakarta, LPIK

Hidayatullah, S. 2000.Intelektualisme dalam Perspektif NeoModernisme. Yogyakarta: Tiara Wacana.

Khozin. 2005. Menggugat Pedidikan Muhammadiyah.Malang: UMM Pres

Kuntowijoyo, dalam Mulkhan, A. M. 2000. Islam Murni dalam Masyarakat Petani, Yogyakarta: Bentang Yayasan Budaya

Kuntowijoyo. 2008. Paradigma Islam: Interpretasi untuk Aksi. Bandung: Mizan

Maarif, A.S. 1993. Peta Bumi Intelektualisme Islam di Indonesia, Bandung: Mizan

Madjid, N. 1997.Bilik-bilik Pesantren: Sebuah Potret Perjalanan. Jakarta: Paramadina 
Mu'arif. 2012. Modernisasi Pendidikan Islam: Sejarah dan Perkembangan Kweekschool Moehammadijah 1923-1932. Yogyakarta: Suara Muhammadiyah

Nashir,H. 2000.Perilaku Politik Elit Muhammadiyah. Yogyakarta: Tarawang

Noer, D. 1980.Gerakan Modern Islam di Indonesia 1900-1942. Jakarta: LP3ES, 1980

Pimpinan Pusat Muhammadiyah, Anggaran Dasar dan Anggaran

Rumah Tanggal Muhammadiyah, (Yogyakarta: Suara Muhammadiyah: 2010), pasal 3.

Riklefs, M.C. 2005.Sejarah Indonesia Modern 1200-2004. Jakarta: Serambi.

Riklefs, M.C. 2005. Sejarah Indonesia Modern. Jakarta: Serambi

Setiawan, F. 2015. Genealogi dan Modernisasi Sistem Pendidikan Muhammadiyah 1911-1942. Yogayakarta: Semesta Ilmu Steenbrink, K. A. 1986. Pesantren, Sekolah, Madrsah: Pendidikan Islam pada Kurun Modern. Jakarta: LP3S

Syuja', K. 2009. Islam Bekemajuan: Kisah Perjuangan Ahmad Dahlan dan Muhammadiyah pada Masa Awal.Jakarta: al-Wasat

Yatim, B. 1997. Sejarah Peradaban Islam. Jakarta: PT. RajaGrafindo Persada 